\author{
한우 도체형질의 유전능력평가를 위한 통계모형 탐색 \\ 구양모 ${ }^{*} \cdot$ 김시동 $^{2} \cdot$ 김정일 $^{1} \cdot$ 송치은 $^{1} \cdot$ 이기환 $^{1} \cdot$ 정용호 $^{1} \cdot$ 이재윤 $^{1} \cdot$ 장현기 $^{1} \cdot$ 박병호 $^{2} \cdot$ 최태정 $^{2} \cdot$ \\ 조광현 ${ }^{2} \cdot$ 이승수 ${ }^{2} \cdot$ 이정규 $^{3} \cdot$ 김효선 ${ }^{4}$ \\ 1한국종축개량협회, ${ }^{2 ㄴ ㅗ ㅇ ㅊ ㅗ ㄴ ㅈ ㅣ ㄴ ㅎ ㅡ ㅇ ㅊ ㅓ ㅇ ~ ㄱ ㅜ ㄱ ㄹ ㅣ ㅂ ㅊ ㅜ ㄱ ㅅ ㅏ ㄴ ㄱ ㅘ ㅎ ㅏ ㄱ ㅇ ㅝ ㄴ, ~}{ }^{3}$ 국립경상대학교 응용생명과학부, ${ }^{4}$ 축산물품질평가원
}

\title{
Research of Statistical Model for Genetic Evaluation of Hanwoo Carcass Traits
}

Yang Mo Koo ${ }^{1 *}$, Si Dong Kim ${ }^{2}$, Jung Il Kim ${ }^{1}$, Chi Eun Song ${ }^{1}$, Ki Hwan Lee ${ }^{1}$, Yeoung Ho Jeoung ${ }^{1}$ Jae Youn Lee ${ }^{1}$, Hyun Gi Jang ${ }^{1}$, Byoung Ho Park ${ }^{2}$, Te Jong Choi ${ }^{2}$, Kwang Hyun Cho ${ }^{2}$, Seung Soo Lee ${ }^{2}$, Jung Gyu Lee ${ }^{1}$ and Hyo Sun Kim ${ }^{4}$ ${ }^{1}$ Korea Animal Improvement Association, Seocho, Seoul 137-871, Korea ${ }^{2}$ National Institute of Animal Science, RDA. Cheonan, 331-801, Korea ${ }^{3}$ Division of Applied Life Science · Institute of Agriculture \& Life Sciences, GyeongSang National University, Jinju 660-701, Korea ${ }^{4}$ Korea Institute for Animal Products Quality Evaluation, Gunpo 435-010, Korea

\begin{abstract}
This study was conducted to study the environment effects on live weight, carcass weight, dressing percentage, eye muscle area, backfat thickness, and marbling score, which are the carcass traits of Hanwoo, based on the estimates and all the possible regression for the selection of variable and significance test for 231,382 heads that underwent the carcass measurements. The average and standard deviation for the live weight, carcass weight, dressing percentage, eye muscle area, backfat thickness, and marbling score were $654.79 \pm 91.61 \mathrm{~kg}, 362.30 \pm 67.15 \mathrm{~kg}, 59.52 \pm 0.03 \%, 81.79 \pm 12.21 \mathrm{~cm}^{2}, 11.39 \pm 5.40 \mathrm{~mm}, 4.38 \pm 2.29$, respectively. The live weight, carcass weight, dressing percentage, eye muscle area, backfat thickness, and marbling score for cow were $532.79 \pm 78.38 \mathrm{~kg}, \quad 313.40 \pm 44.90 \mathrm{~kg}, 56.50 \pm 0.03 \%, \quad 75.24 \pm 10.69 \mathrm{~cm}^{2}, 11.82 \pm 5.10 \mathrm{~mm}, 4.30 \pm 2.06$, respectively, while for bull were $619.74 \pm 93.27 \mathrm{~kg}, \quad 376.89 \pm 48.62 \mathrm{~kg}, \quad 58.61 \pm 0.02 \%, \quad 85.61 \pm 10.46 \mathrm{~cm}^{2}, \quad 5.64 \pm 2.71 \mathrm{~mm}, \quad 1.41 \pm 0.83$, respectively, and for steer were $681.78 \pm 70.72 \mathrm{~kg}, 415.23 \pm 49.43 \mathrm{~kg}, 60.19 \pm 0.02 \%, 88.29 \pm 10.27 \mathrm{~cm}^{2}, 12.71 \pm 5.23 \mathrm{~mm}, 5.42 \pm 1.99$, respectively. In the environmental variables selection based on the variables selection method, the examination by carcass traits suggested that the most appropriate model could be determined when five variables were selected for the live weight, carcass weight, dressing percentage, eye muscle area, and four variables for backfat thickness, and marbling score. When they were considered at a time altogether based on multiple traits, it was deemed to be desirable to insert all five variables into the variables for analysis. In addition, high significance was found by carcass traits.
\end{abstract}

(Key words : Hanwoo, Carcass traits, Variable selection, Statistical model)

서 론

현재 농가에서 사육하고 있는 암소에 대한 농가차원의 능력검정 은 거의 이루어지지 않고 있고, 농림수산식품부의 한우개량사업에 참여하고 있는 농가 보유 암소에 대한 혈통이 현재까지 암소사육 농가에서 얻을 수 있는 최선의 정보이다. 이러한 상황에서 농가의 암소에 대한 유전능력평가를 실시한다는 것은 모래위에 성을 쌓는 것과 같다. 그동안 한우도체형질에 대한 환경요인 추정에 대한 연 구 유전능력평가에 대한 많은 연구(Yoon et al., 2002, Roh et al., 2004, Choi et al., 2006, Hwang et al., 2008, and Koo et al., 2008)가 지속적으로 이루어져 왔으나 도축된 개체와 혈통이 연계되는 확률이 지금보다 낮아서 많은 어려움을 주었다. 하지만
쇠고기 생산이력제가 도입되면서 등급판정결과와 개체번호를 결합 하고 이 정보를 다시 한국종축개량협회의 혈통등록 정보와 결합시 킬 경우 암소 자기 자신 또는 암소의 자손(거세, 비거세)에 대한 도축성적을 얻을 수 있는 제도적 장치가 마련되었다. 따라서 본 연 구는 축산물품질평가원에서 2006 2009년까지 등급판정한 개체 중 한국종축개량협회에 등록된 개체 231,382 두에 대하여 각 도체 형질 자료를 구조 분석하고 각 요인별로 도체형질에 어떠한 영향을 주는 지에 대한 환경효과를 분석하고, 변수선택법 등을 이용하여 향후 유전능력평가에서 사용 가능한 통계모형 찾아내고자 실시하였 다. 그리고 더 나아가 도체정보와 개체식별번호 정보를 수집하고 이를 한국종축개량협회의 혈통등록 정보와 결합하여 농가보유 암소 에 대한 유전능력평가를 위한 기초자료로 제공하고자 이번 연구를

* Corresponding author: Yang Mo Koo, Planning \& Breeding Team, Korea Animal Improvement Association, Seocho-dong Seocho-gu, Seoul, Korea, 137-871. Tel: +82-2-588-9301, Fax: +82-2-582-3475, E-mail: greatman009@hanmail.net 
실시하였다.

\section{재료 및 방법}

\section{1. 분석자료}

본 연구에 이용된 재료는 2006년부터 2009년까지 축산물품질평 가원에서 등급 판정된 개체 중 한국종축개량협회에서 등록된 개체 확인 후 이상치를 제외한 231,382 두의 기록을 이용하였다. 평가를 위하여 성별, 출생년도, 출생계절, 도축년도, 도축계절, 출생지역으 로 나누어 분석하였다. 각 모형에 이용된 자료 등에 대한 일반 정 보는 Table 1에 표시한 바와 같다. 분석한 형질은 출하체중 (Live weight $(\mathrm{LW}), \mathrm{kg})$, 도체중 (Carcass Weight $(\mathrm{CW}), \mathrm{kg})$, 도체율 (Dressing Percentage(DP), \%), 배최장근단면적 (Eye Muscle Area (EMA), $\mathrm{cm}^{2}$ ), 등지방두께 (Backfat Thickness (BF), mm), 근내지방도(Marbling Score(MS), score)이다. 2006년부터 2009년 까지의 등급 판정 성적을 이용한 것은 쇠고기생산이력제가 2004년 10 월부터 일부 브랜드 경영체와 시·군을 중심으로 추진되었고, 2006 년에 전국 20 여 개 브랜드 경영체와 3 개 시, 군이 참여하여 사업을 확대 추진하였기 때문에 개체 확인 및 등록여부가 사업 실 시 이전의 도체성적 자료보다 일치되는 개체가 많았기 때문이다.

\section{2. 통계분석}

(1) 일반분석 및 정규성 검정

도체형질의 일반분석에서는 각 형질별 일반성적을 분석하여 암, 수, 거세, 그리고 성별을 통합한 전체자료에 대한 기술통계량을 살 펴보고, 자료의 정규성을 파악하기 위하여 각 형질별 분포를 나타
내어 정규분포에 근사되는지를 파악하였다.

일반 성적을 분석하기 위하여 SAS MEANS Procedure를 이용 하여 두수, 최소, 최대, 평균, 변이계수를 추정하였다. 정규분석은 SAS UNIVARIATE Procedure의 Checking Variables for Normality를 이용하여 Kolmogorov-Smirnov 통계량(D)으로 검정 을 하였고 Kolmogorov-Smirnov 통계량(D) 추정을 위한 공식은 다음과 같다.

$$
\mathrm{D}=\sup _{\mathrm{x}}\left|\mathrm{F}_{\mathrm{n}}(\mathrm{x})-\mathrm{F}(\mathrm{x})\right|
$$

\section{(2) 환경효과}

한우 도체형질에 영향을 미치는 성별, 출생년도, 출생계절, 출생 지역, 도축일령의 환경효과를 추정하기 위하여 다음과 같은 선형 모형을 사용하였다.

$\mathrm{Y}_{\mathrm{ijkl}}=\mu+\mathrm{Sex}_{\mathrm{i}}+\mathrm{YOB}_{\mathrm{j}}+\mathrm{SOB}_{\mathrm{k}}+\mathrm{AOB}_{1}+\beta \mathrm{age}_{\mathrm{ijkl}}(\mathrm{Cov})+\mathrm{e}_{\mathrm{ijkl}} \cdots(1)$ 여기서,

\begin{tabular}{|c|c|}
\hline$Y_{i j k l}$ & : 관측치 \\
\hline$\mu$ & 전체평균 \\
\hline $\operatorname{Sex}_{\mathrm{i}}$ & $\mathrm{i}$ 번째 성별의 고정효과 (i=1 3) \\
\hline $\mathrm{YOB}_{j}$ & $\mathrm{j}$ 번째 출생년도 고정효과 $(\mathrm{j}=1$ 6) \\
\hline $\mathrm{SOB}_{\mathrm{k}}$ & $: \mathrm{k}$ 번째 출생계절의 고정효과 $(\mathrm{k}=1$ 4) \\
\hline $\mathrm{AOB}_{1}$ & : 1번째 출생지역의 고정효과 (n=1 9) \\
\hline Cage $_{i j k l}$ & : 도축일령에 대한 공변이 (Covariate) \\
\hline$e_{i j k l}:$ & 정치의 임의오차 \\
\hline
\end{tabular}

(1)의 선형 모형식을 풀기 위하여 PC용 SAS Package Ver. 9.1 을 이용하여 분석을 실시하였다.

Table 1. Number of records by sex, year of birth, season of birth, area of birth

\begin{tabular}{|c|c|c|c|c|c|c|c|}
\hline Sex & No. & $\mathrm{YOB}^{1)}$ & No. & $\mathrm{SOB}^{2)}$ & No. & $\mathrm{AOB}^{3)}$ & No. \\
\hline Cow & 109,158 & 2002 & 12,516 & Spring & 71,894 & GG & 27,845 \\
\hline Bull & 29,499 & 2003 & 11,064 & Summer & 47,542 & GW & 28,569 \\
\hline \multirow[t]{7}{*}{ Steer } & 92,725 & 2004 & 19,901 & Fall & 32,315 & $\mathrm{CB}$ & 19,854 \\
\hline & & 2005 & 35,197 & Winter & 79,631 & $\mathrm{CN}$ & 18,678 \\
\hline & & 2006 & 105,704 & & & JB & 23,429 \\
\hline & & 2007 & 47,000 & & & $\mathrm{JN}$ & 31,354 \\
\hline & & & & & & GB & 34,890 \\
\hline & & & & & & GN & 44,761 \\
\hline & & & & & & $\mathrm{JJ}$ & 2,002 \\
\hline Total & 231,382 & Total & 231,382 & Total & 231,382 & Total & 231,382 \\
\hline
\end{tabular}

${ }^{1)}$ YOB: Year of birth, ${ }^{2)}$ SOB: Season of birth, ${ }^{3)}$ AOB: Area of birth, GG: Gyeonggi, GW: Gangwon, CB: Chungbuk, CN: Chungnam, JB: Jeonbuk, JN: Jeonnam, GB: Gyeongbuk, GN: Gyeongnam, JJ: Jeju. 
(3) 변수선택

환경효과 분석에서 중요한 것 중의 하나가 환경효과의 수가 많은 경우에 고려하고 있는 모든 환경효과를 모형에 포함시킬 것인가 하 는 문제가 발생하여 환경효과를 모두 회귀모형에 포함하였으며, 환 경요인들 중 일부만을 포함하는 회귀모형보다 결정계수의 값이 크 고 설명력을 최대화 되도록 분석하였다. 하지만 가능한 모든 환경 효과들을 회귀모형에 포함시키면 환경효과들 간의 상관관계가 커지 는 단점이 있어 모형의 안정성과 신뢰성에 의문이 생길 수 있기 때 문에 $\mathrm{R}^{2}$ 와 $\mathrm{MSE}$ (Mean squared error) 그리고 $\mathrm{C}_{\mathrm{p}}$ 통계량으로 모 든 가능한 회귀 (All possible regression) 방법을 통하여 모든 가 능한 변수들의 조합을 회귀 분석한 다음, $\mathrm{C}_{\mathrm{p}}$ 통계량을 기준으로 하 고 $\mathrm{R}^{2}$ 와 $\mathrm{MSE}$ 를 참조하여 적정 모형을 선택하였다.

변수선택에 포함된 환경효과는 앞에서 분석한 성별, 출생년도, 출생계절, 출생지역과 추가적으로 도축년도와 도축계절 그리고 도 축월령을 삽입하여 모형적합도 검정을 실시하였다. 또한 분석을 위 하여 출생년도와 출생계절은 출생년도-계절, 도축년도와 도축계절 은 도축년도-계절로 묶어서 분석을 실시하였다.

변수선택을 위해 적용한 Full model은 (2)와 같다.

$$
\begin{aligned}
& \mathrm{Y}_{\mathrm{i}}=\beta_{0}+\beta_{1} \mathrm{X}_{1 \mathrm{i}}+\beta_{2} \mathrm{X}_{2 \mathrm{i}}+\beta_{3} \mathrm{X}_{3 \mathrm{i}}+\beta_{4} \mathrm{X}_{4 \mathrm{i}}+\beta_{5} \mathrm{X}_{5 \mathrm{i}}+\mathrm{e}_{\mathrm{i}} \cdots \cdots(2) \\
& \text { 여기서 } \mathrm{i}=1,2, \cdots, \mathrm{n}
\end{aligned}
$$

(2)의 회귀분석 모형에서는 전체 5 가지의 변수로 적용하였으며, 해당 변수는 각각 $\mathrm{X} 1$ 은 성별, $\mathrm{X} 2$ 는 출생년도-계절, $\mathrm{X} 3$ 은 도축년 도-계절, $\mathrm{X} 4$ 는 출생지역, $\mathrm{X} 5$ 는 도축월령으로 구성되어져 있다. 또한 분석 중 각 모형에 대한 $\mathrm{R}^{2}$ 와 $\mathrm{C}_{\mathrm{p}}$ 통계량 그리고 $\mathrm{MSE}$ 추정
을 위한 공식은 (3) (5)에 나타내었다.

$$
\begin{aligned}
& \mathrm{R}^{2}=1-\frac{\mathrm{SSE}}{\mathrm{SSA}-\overline{\mathrm{y}^{2}} \times \mathrm{n}} \cdots \cdots \cdots \cdots \cdots \cdots \cdots \cdots \cdots \cdots \cdots \cdots \cdots \cdots \cdots \\
& \mathrm{C}_{\mathrm{p}}=\left[\left(\mathrm{SSE}_{\mathrm{p}}\right) /\left(\mathrm{S}^{2}\right)\right]-(\mathrm{N}-2 \mathrm{p}) \cdots \cdots \cdots \cdots \cdots \cdots \cdots \cdots \cdots \cdots \cdots \cdots \cdots \cdots \\
& \operatorname{MSE}\left(\overline{\mathrm{Y}_{\mathrm{i}}}\right)=\left[\mathrm{E}\left(\overline{\mathrm{Y}_{\mathrm{i}}}\right)-\mathrm{E}\left(\mathrm{Y}_{\mathrm{i}}\right)\right]^{2}+\operatorname{var}\left(\overline{\mathrm{Y}_{\mathrm{i}}}\right) \quad \cdots \cdots \cdots \cdots \cdots \cdots
\end{aligned}
$$

분석을 위해서 SAS REG Procedure의 Selection option을 활 용하였다.

\section{결과 및 고찰}

\section{1. 일반분석}

\section{(1) 자료 구조 분석}

Table 2는 한우 도체형질의 정규성 검정 결과이다. K-S통계량 (Kolmogorov Smirnov statistic)이 0.05보다 큰 경우는 정규분포 를 보이고, 0.05 보다 작은 경우에는 정규분포가 되지 않는다 (Kolmogorov, A. N. 1933 and Smirnov, N. V. 1939.). 한우 암 소집단에서는 도체율과, 등지방두께 그리고 근내지방도에서 정규성 을 나타내고 있으며, 수소 집단에서는 배최장근단면적과 등지방두 께 그리고 근내지방도에서 정규성이 나타났고, 거세우 집단에서는 등지방두께와 근내지방도에서 정규성이 나타났으며, 도체율은 정규

\begin{tabular}{|c|c|c|c|c|c|c|}
\hline Source & LW & $\mathrm{CW}$ & $\mathrm{DP}$ & EMA & $\mathrm{BF}$ & MS \\
\hline \multicolumn{7}{|l|}{ Cow } \\
\hline No & 6,708 & 109,158 & 6,708 & 109,158 & 109,158 & 109,158 \\
\hline $\mathrm{K}-\mathrm{S} \mathrm{Z}^{1)}$ & 0.045 & 0.033 & 0.057 & 0.046 & 0.115 & 0.117 \\
\hline \multicolumn{7}{|l|}{ Bull } \\
\hline No & 2,102 & 29,499 & 2,102 & 29,499 & 29,499 & 29,499 \\
\hline K-S Z & 0.033 & 0.027 & 0.040 & 0.060 & 0.163 & 0.420 \\
\hline \multicolumn{7}{|l|}{ Steer } \\
\hline No & 33,052 & 92,725 & 33,052 & 92,725 & 92,725 & 92,725 \\
\hline K-S Z & 0.026 & 0.027 & 0.048 & 0.018 & 0.099 & 0.123 \\
\hline \multicolumn{7}{|l|}{ Total } \\
\hline No & 41,862 & 231,382 & 41,862 & 231,382 & 231,382 & 231,382 \\
\hline K-S Z & 0.059 & 0.032 & 0.055 & 0.031 & 0.093 & 0.113 \\
\hline
\end{tabular}
성에 근접하였다. 전체적으로는 출하체중, 도체율, 등지방두께, 근 내지방도에서 정규성이 나타났으며, 다른 형질에서도 정규성에 근 접함을 확인할 수 있었다.

Table 2. Kolmogorov-Smirnov test of carcass traits

${ }^{1)} \mathrm{K}-\mathrm{S}$ Z: Kolmogorov-Smirnov statistic, LW: Live weight $(\mathrm{kg}), \mathrm{CW}$ : Carcass weight $(\mathrm{kg})$, DP: Dressing percentage (\%), EMA: Eye muscle area $\left(\mathrm{cm}^{2}\right)$, BF: Backfat thickness (mm), MS: Marbling score $\mathrm{p}>0.05$ : Normal distribution, $\mathrm{p}<0.05$ : Not normal distribution. 
(2) 일반성적

Table 3은 성별에 따른 한우 도체형질에 대한 기초통계량이다.

전체자료를 살펴보면 출하체중, 도체중, 도체율, 배최장근단면적, 등지방두께, 근내지방도는 각각 $654.79 \pm 91.61 \mathrm{~kg}, 362.30 \pm 67.15$ $\mathrm{kg}, 59.52 \pm 0.03 \%, 81.79 \pm 12.21 \mathrm{~cm}^{2}, 11.39 \pm 5.40 \mathrm{~mm}, 4.38 \pm 2.29$ 로 추정되었다. 도체중의 경우 2004년 Crew 등이 6,937두의 Simmental steer로 추정한 $349.0 \pm 31.6 \mathrm{~kg}, 2004$ 년 Eriksson 등이 5,260 두의 Charolais bull로 추정한 $359.1 \pm 46.3 \mathrm{~kg}$ 그리고 2008
년 구 등이 1,587 두의 한우거세우로 추정한 $377.3 \pm 45.6 \mathrm{~kg}$ 과 비슷 하게 나타났다.

\section{2. 환경효과 분석}

한우 도체형질 6가지에 대한 분산분석 결과는 Table 4에 나타내 었다. 각 환경효과에 대한 분산분석 결과를 살펴보면 출하체중 $(\mathrm{LW})$, 도체중 $(\mathrm{CW})$, 도체율 $(\mathrm{DP})$, 배최장근단면적 $(\mathrm{EMA})$, 등지방

Table 3. Descriptive statistics for carcass traits of Hanwoo

\begin{tabular}{|c|c|c|c|c|c|c|}
\hline Carcass trait & No. & Mean & Std & Min & Max & $\left.\mathrm{CV}^{6}\right)$ \\
\hline \multicolumn{7}{|l|}{ Cow } \\
\hline Live $\mathrm{wt}^{1)}, \mathrm{kg}$ & 6,708 & 532.79 & 78.38 & 232.00 & 885.00 & 14.71 \\
\hline Carcass $\mathrm{wt}^{1}, \mathrm{~kg}$ & 109,158 & 313.40 & 44.90 & 118.00 & 624.00 & 14.33 \\
\hline $\mathrm{DP}^{2)}, \%$ & 6,708 & 56.50 & 0.03 & 32.95 & 89.66 & 5.80 \\
\hline $\mathrm{EMA}^{3)}, \mathrm{cm}^{2}$ & 109,158 & 75.24 & 10.69 & 21.00 & 134.00 & 14.21 \\
\hline $\mathrm{BF}^{4)}, \mathrm{mm}$ & 109,158 & 11.82 & 5.10 & 1.00 & 61.00 & 43.15 \\
\hline $\mathrm{MS}^{5}$ & 109,158 & 4.30 & 2.06 & 1.00 & 9.00 & 47.96 \\
\hline \multicolumn{7}{|l|}{ Bull } \\
\hline Live $\mathrm{wt}^{1)}, \mathrm{kg}$ & 2,102 & 619.74 & 93.27 & 311.00 & 911.00 & 15.05 \\
\hline Carcass $\mathrm{wt}^{1)}, \mathrm{kg}$ & 29,499 & 376.89 & 48.62 & 152.00 & 638.00 & 12.90 \\
\hline $\mathrm{DP}^{2)}, \%$ & 2,102 & 58.61 & 0.02 & 40.51 & 68.84 & 3.99 \\
\hline $\mathrm{EMA}^{3)}, \mathrm{cm}^{2}$ & 29,499 & 85.61 & 10.46 & 20.00 & 139.00 & 12.22 \\
\hline $\mathrm{BF}^{4)}, \mathrm{mm}$ & 29,499 & 5.64 & 2.71 & 1.00 & 28.00 & 47.98 \\
\hline $\mathrm{MS}^{5)}$ & 29,499 & 1.41 & 0.83 & 1.00 & 3.00 & 58.68 \\
\hline \multicolumn{7}{|l|}{ Steer } \\
\hline Live $\mathrm{wt}^{1)}, \mathrm{kg}$ & 33,052 & 681.78 & 70.72 & 276.00 & $1,011.00$ & 10.37 \\
\hline Carcass $\mathrm{wt}^{1)}, \mathrm{kg}$ & 92,725 & 415.23 & 49.43 & 139.00 & 658.00 & 11.90 \\
\hline $\mathrm{DP}^{2)}, \%$ & 33,052 & 60.19 & 0.02 & 38.75 & 89.26 & 3.60 \\
\hline $\mathrm{EMA}^{3)}, \mathrm{cm}^{2}$ & 92,725 & 88.29 & 10.27 & 20.00 & 142.00 & 11.63 \\
\hline $\mathrm{BF}^{4)}, \mathrm{mm}$ & 92,725 & 12.71 & 5.23 & 1.00 & 54.00 & 41.13 \\
\hline $\mathrm{MS}^{5)}$ & 92,725 & 5.42 & 1.99 & 1.00 & 9.00 & 36.71 \\
\hline \multicolumn{7}{|l|}{ Total } \\
\hline Live $\mathrm{wt}^{1)}, \mathrm{kg}$ & 41,862 & 654.79 & 91.61 & 232.00 & $1,011.00$ & 13.99 \\
\hline Carcass $\mathrm{wt}^{1)}, \mathrm{kg}$ & 231,382 & 362.30 & 67.15 & 118.00 & 658.00 & 18.54 \\
\hline $\mathrm{DP}^{2)}, \%$ & 41,862 & 59.52 & 0.03 & 32.95 & 89.66 & 4.62 \\
\hline $\mathrm{EMA}^{3)}, \mathrm{cm}^{2}$ & 231,382 & 81.79 & 12.21 & 20.00 & 142.00 & 14.93 \\
\hline $\mathrm{BF}^{4)}, \mathrm{mm}$ & 231,382 & 11.39 & 5.40 & 1.00 & 61.00 & 47.41 \\
\hline $\mathrm{MS}^{5)}$ & 231,382 & 4.38 & 2.29 & 1.00 & 9.00 & 52.24 \\
\hline
\end{tabular}

${ }^{1)}$ wt: Weight, ${ }^{2)}$ DP: Dressing Percentage, ${ }^{3)}$ EMA: Eye muscle area, ${ }^{4)} \mathrm{BF}$ : Backfat Thickness, ${ }^{5)} \mathrm{MS}$ : Marbling score, ${ }^{6} \mathrm{CV}$ : Coefficient of variation. 
Table 4. Source of the variation, degree of freedom, mean square and test of significance for each trait studied

\begin{tabular}{ccrrrrrr}
\hline Source & D.F & LW & CW & DP & EMA & BF & MS \\
\hline \hline Sex & 2 & $46839637.5^{* *}$ & $186708260.2^{* *}$ & $2.509^{* *}$ & $3143476.1^{* *}$ & $418399.5^{* *}$ & $142433.2^{* *}$ \\
YOB $^{1)}$ & 5 & $7888622.5^{* *}$ & $30222532.7^{* *}$ & $0.538^{* *}$ & $552660.4^{* *}$ & $59547.6^{* *}$ & $7094.2^{* *}$ \\
SOB $^{2)}$ & 3 & $1345132.1^{* *}$ & $1441522.1^{* *}$ & $0.139^{* *}$ & $40084.1^{* *}$ & $9602.1^{* *}$ & $1083.8^{* *}$ \\
AOB $^{3)}$ & 8 & $313301.6^{* *}$ & $807933.6^{* *}$ & $0.030^{* *}$ & $40692.7^{* *}$ & $10333.5^{* *}$ & $236.9^{* *}$ \\
Cage $^{4)}$ & 1 & $16558245.9^{* *}$ & $16695272.7^{* *}$ & $0.348^{* *}$ & $473041.7^{* *}$ & $23031.4^{* *}$ & $3148.6^{* *}$ \\
Error & 231381 & 4799.2 & 2077 & 0.0005 & 105.44 & 23.14 & 3.618 \\
\hline
\end{tabular}

${ }^{1)}$ YOB: Year of birth, ${ }^{2)}$ SOB: Season of birth, ${ }^{3)} \mathrm{AOB}$ : Area of birth, ${ }^{4)}$ Cage: Age at slaughter, LW: Live weight (kg), CW: Carcass weight $(\mathrm{kg})$, DP: Dressing percentage (\%), EMA: Eye muscle area $\left(\mathrm{cm}^{2}\right)$, BF: Backfat thickness (mm), MS: Marbling score $* *: \mathrm{p}<0.01$.

Table 5. All possible regression of variable selection method for carcass traits

\begin{tabular}{|c|c|c|c|c|c|}
\hline Trait & Model & R-Square $^{1)}$ & $\mathrm{C}_{\mathrm{p}}^{2)}$ & $\mathrm{MSE}^{3)}$ & Variables in Model $^{4)}$ \\
\hline LW & 5 & 0.39 & 6.00 & $5,154.07$ & $\mathrm{X} 1 \mathrm{X} 2 \mathrm{X} 3 \mathrm{X} 4 \mathrm{X} 5$ \\
\hline $\mathrm{CW}$ & 5 & 0.42 & 6.00 & $2,371.22$ & $\mathrm{X} 1 \mathrm{X} 2 \mathrm{X} 3 \mathrm{X} 4 \mathrm{X} 5$ \\
\hline $\mathrm{CP}$ & 5 & 0.25 & 6.00 & 0.0006 & $\mathrm{X} 1 \mathrm{X} 2 \mathrm{X} 3 \mathrm{X} 4 \mathrm{X} 5$ \\
\hline EMA & 5 & 0.18 & 6.00 & 112.63 & $\mathrm{X} 1 \mathrm{X} 2 \mathrm{X} 3 \mathrm{X} 4 \mathrm{X} 5$ \\
\hline $\mathrm{BF}$ & 4 & 0.06 & 4.01 & 27.18 & $\mathrm{X} 1 \mathrm{X} 2 \mathrm{X} 4 \mathrm{X} 5$ \\
\hline MS & 4 & 0.14 & 5.65 & 4.14 & $\mathrm{X} 1 \mathrm{X} 2 \mathrm{X} 4 \mathrm{X} 5$ \\
\hline
\end{tabular}

${ }^{1)} \mathrm{R}^{2}$ : Coefficient of determination, ${ }^{2)} \mathrm{C}_{\mathrm{p}}$ : Mallow's statistic, ${ }^{3)} \mathrm{MSE}:$ Mean square error, Variables in Model : X1=sex, X2=year of birth and season of birth, $\mathrm{X} 3=$ year of slaughter and season of slaughter, $\mathrm{X} 4=$ area of birth, $\mathrm{X} 5=$ month of slaughter.

두께 $(\mathrm{BF})$, 근내지방도 $(\mathrm{MS})$ 는 성별, 출생년도, 출생계절, 출생지역, 도축일령에서 모두 고도의 유의성 $(\mathrm{p}<0.01)$ 이 인정되었다.

\section{3. 변수선택 및 통계모형 탐색}

적절한 선택기준에 의하여 효과적인 방법으로 환경효과를 선택함 으로써 유전능력평가시 개체의 능력에 미치는 환경효과를 적절히 제거할 수 있도록 변수선택을 통하여 Table 5에서 한우 도체형질 에 적합한 통계모형을 탐색해 보았다.

Table 5에서 보는 바와 같이 출하체중은 다섯 가지 환경효과(성 별, 출생년도-계절, 도축년도-계절, 출생지역, 출하월령)를 적용하 였을 경우 $\mathrm{R}^{2}=0.39, \mathrm{C}_{\mathrm{p}}=6.00, \mathrm{MSE}=5,154.07$ 로 최적의 모형을 설 정할 수 있다. 도체중과 도체율, 배최장근단면적에서도 다섯 가지 환경효과를 적용하였을 경우 각각 $\mathrm{R}^{2}=0.42, \mathrm{C}_{\mathrm{p}}=6.00, \mathrm{MSE}=$ $2,371.22$ 과 $\mathrm{R}^{2}=0.25, \mathrm{C}_{\mathrm{p}}=6.00, \mathrm{MSE}=5.68$ 그리고 $\mathrm{R}^{2}=0.18$, $\mathrm{C}_{\mathrm{p}}=6.00, \mathrm{MSE}=112.63$ 으로 모형이 가장 적합하게 나타났다. 그 리고 등지방두께와 근내지방도는 네 가지 환경효과(성별, 출생년도 -계절, 출생지역, 출하월령)를 적용하였을 경우 각각 $\mathrm{R}^{2}=0.06$, $\mathrm{C}_{\mathrm{p}}=4.01, \mathrm{MSE}=27.18$ 과 $\mathrm{R}^{2}=0.14, \mathrm{C}_{\mathrm{p}}=5.65, \mathrm{MSE}=4.14$ 로 이때
가장 적합한 모형을 보이는 것으로 판단되었다. 출하체중, 도체중, 도체율, 배최장근단면적은 다섯 가지 환경효과를 선택하는 것이 최 적이었고, 등지방두께와 근내지방도는 네 가지 환경효과를 고려하 는 것이 최적이었지만, 다형질 분석으로 한 번에 분석을 하기 위해 서는 다섯 가지 환경효과를 함께 고려하는 것이 적합하다고 사료된 다. 하지만, 자료별 구조 및 특성이 다르기 때문에 모든 한우 도체 형질 자료를 상기 모형에 적용하는 것에는 지속적인 분석과 해석이 이루어져야 한다고 판단되었다. 또한 향후 한우 도체형질의 유전능 력평가에 필요한 유전모수와 암소의 개량 정도를 고찰하고 암소검 정사업 등에서 농가 보유 암소 개체별 유전능력평가를 할 수 있는 유전능력평가 컴퓨터 프로그램 개발이 추가적으로 이루어져야 할 것으로 사료된다.

$$
\text { 요 약 }
$$

2006년부터 2009년까지 축산물품질평가원에서 등급 판정된 도 체성적이 있는 개체와 한국종축개량협회에 등록이 확인된 231,382 두의 자료를 이용하여 각 도체형질의 자료구조 분석 등을 살펴보 고, 각 요인별로 도체형질에 어떠한 영향을 주는 지에 대한 환경효 
과 등을 분석하고, 변수선택법 등을 이용하여 향후 유전능력평가에 서 사용 가능한 통계모형 찾아내고자 실시하였다.

한우 암, 수, 거세를 포함한 전체집단에서 출하체중, 도체율, 등 지방두께, 근내지방도에서 정규분포를 보이고 있었고, 다른 형질은 정규분포에 근접함을 확인할 수 있었다. 각 요인에 대한 분산분석 에서는 한우 도체형질에 대하여 성별, 출생년도-계절, 도축년도계절, 출생지역, 도축일령의 모두 고도의 유의성 $(\mathrm{p}<0.01)$ 이 인정되 었다.

변수선택법을 이용한 모형적합도 검정에서는 출하체중, 도체중, 도체율, 배최장근단면적은 다섯 가지 환경효과를 선택하는 것이 최적이었고, 등지방두께와 근내지방도는 네 가지 환경효과를 고려 하는 것이 최적이었지만, 다형질 분석으로 한 번에 분석을 하기 위해서는 다섯 가지 환경효과를 함께 고려하는 것이 적합하다고 사료된다.

(주제어: 한우, 도체형질, 변수선택, 통계모형)

\section{인 용 문 헌}

Choi, T. J., Kim, S. D., Agapita J. Salces and Baik, D. H. 2006. Genetic Parameter Estimation on the Growth and Carcass Traits in Hanwoo (Korean Cattle). J. Anim. Sci. \& Technol. (Kor.) 48(6):759-766

Crews, D. H., Jr., Pollak, E. J. and Quaas, R. L. 2004. Evaluation of Simmental carcass EPD estimated using live and carcass data. J. Anim. Sci. 82:661-667.

Eriksson, S., Nasholm, A., Johansson, K. and Philipsson, J. 2004. Genetic relationships between calving and carcass traits for Charolais and Hereford cattle in Sweden. J. Anim. Sci. 82:
2269-2276

Jeong, Mi Hwang, Kim, Si dong, Choy, Yun Ho, Yoon, Ho Baek and Park, Cheol Jin. 2008. Genetic Parameter Estimation of Carcass Traits of Hanwoo Steers. J. Anim. Sci. \& Technol. (Kor.) 50(5):613-620.

Kolmogorov, A. N. 1933. "On the Empirical Determination of a Distribution Function”, vol.4, pp.83-91.

Koo, Yang Mo, Kim, Jung Il, Song, Chi Eun, Shin, Jae Young, Lee, Jong Heon, Cho, Byoung Dai, Kim, Byeong Woo and Lee, Jung Gyu. 2008. A Study on Genetic Parameters of Carcass Weight and Body Type Measurements in Hanwoo Steer. J. Anim. Sci. \& Technol. (Kor.) 50(2):157-166.

Roh, S. H., Kim, B. W., Kim, H. S., Min, H. S., Yoon, H. B., Lee, D. H., Jeon, J. T. and Lee, J. G. 2004. Comparison between REML and Bayesian via Gibbs Sampling Algorithm with a Mixed Animal Model to Estimate Genetic Parameters for Carcass Traits in Hanwoo (Korean Native Cattle). J. Anim. Sci. \& Technol. (Kor.) 46(5):719-728.

SAS. Inst. Inc. 2004. SAS/STAT 9.1 user's Guide. SAS Inst. Inc., Cary, NC, USA.

Smirnov, N. V. 1939. "On the Estimation of the Discrepency between Empirical Curves of Distribution for Two Independent Samples", Bulletin of Moscow, vol.2, pp.3-16.

Yoon, H. B., Kim., S. D., Na, S. H., Chang, U. M., Lee, H. K., Jeon, G. J. and Lee, D. H. 2002. Estimation of Genetic Parameters for Carcass Traits in Hanwoo Steer. J. Anim. Sci. \& Technol. (Kor.) 44(4):383-390

(Received Nov. 11, 2010; Revised Jul. 29, 2011; Accepted Aug. 10, 2011) 